\title{
Políticas de philia como traduções das turbulentas sociabilidades escolares: a circulação do reconhecimento como referência na constituição dos laços políticos ${ }^{1}$
}

\author{
Philia politics as translations of turbulent school socialities: \\ circulation of knowledge as reference in the constitution \\ of political ties
}

\section{José Manuel Resende}

Sociólogo, professor catedrático de Sociologia na Universidade de Évora, consultor internacional do Instituto de Estudos Comparados em Administração e Conflitos (InEAC), consultor do Instituto Vladimir Herzog de São Paulo, colaborador do Programa de Pós-Graduação de Sociologia Política da Universidade Estadual do Norte Fluminense Darcy Ribeiro (Uenf), pesquisador integrado do Centro Interdisciplinar de Ciências Sociais (CICS.NOVA) do polo da Universidade de Évora e colaborador do Observatório Permanente da Juventude do Instituto de Ciências Sociais da Universidade de Lisboa.

\section{Resumo}

O artigo pretende desenvolver o conceito de políticas de amizade com o propósito de analisar suas consequências na construção das sociabilidades escolares, em particular, as vias sinuosas e tensionais da produção do reconhecimento de si e dos outros nas escolas secundárias portuguesas. Quais são os limites das políticas de philia, experimentadas na escola, na constituição dos laços políticos entre os atores que habitam essas arenas públicas? Que efeitos produzem as políticas

\footnotetext{
Este texto foi escrito no português de Portugal e baseia-se na palestra proferida na $28^{\text {a }}$ Reunião Anual da Associação Brasileira de Antropologia realizada na cidade de São Paulo entre os dias 2 a 7 de julho de 2012. Subordinada ao tema geral Desafios Antropológicos Contemporâneos, esta comunicação foi apresentada numa mesa redonda organizada por Fábio Reis Mota que teve como tema geral Formas contemporâneas de (re)conhecimento: sociedades plurais e direitos diferenciados. No decurso desta mesa redonda houve a oportunidade de discutir problemas diversos e partilhar conhecimentos, quer com os colegas Luís Roberto Cardoso de Oliveira e Alain Battegay, quer com a audiência presente, cujos comentários são absorvidos aqui. Aproveito esta oportunidade para agradecer publicamente a Fábio Reis Mota pela possibilidade de ali ter estado presente, e aquela que me é dada agora para divulgar junto da comunidade dos antropólogos e das ciências sociais brasileiros as reflexões que tenho produzido sobre este tema ao longo da minha trajetória como sociólogo em Portugal. Por outro lado, este texto dá relevo a um conjunto de questões trabalhadas no projeto "Género, Desigualdade e Humilhação: sentimentos de injustiça nas escolas" - PIHM/GC/0085/2008 - financiado em 2009 (2009-12) conjuntamente pela Fundação para a Ciência e Tecnologia e pela Comissão para a Cidadania e Igualdade de Gênero.
} 
de philia nos processos de reconhecimento do outro, num momento em que a exploração e a experimentação da individuação são uma marca da modernidade contemporânea? Exploramos no artigo um esboço de itinerários para questionar os dilemas dos processos de reconhecimento nos estabelecimentos de ensino.

Palavras-chave: Escolas, Sociabilidades, Conflitos, Operações Críticas, Reconhecimento.

\section{Abstract}

This article intends to develop the concept of friendship politics with the purpose of analyzing its consequences in the construction of school sociability, particularly, the sinuous and tensional ways of producing recognition of the self and others in Portuguese secondary schools. What are the limits of philia policies, experienced in school, in the constitution of political bonds between the actors who inhabit these public arenas? What effects do philia policies produce in the processes of recognizing the other, at a time when the exploration and experimentation of individuation is a mark of contemporary modernity? We explored in this article an outline of itineraries to question the dilemmas of recognition processes in educational establishments.

Keywords: Schools, Sociability, Conflicts, Critical Operations, Recognition.

\section{GUARDAR A LÍNGUA (RE) ATUALIZANDO AS LINGUAGENS: (DES) CONFORMIDADES E RECONHECIMENTO}

Numa incursão não voluntária ao Museu da Língua Portuguesa, sediado na cidade de São Paulo, deparo mais uma vez com a interrogação sobre o lugar da instituição escolar nas sociedades modernas, mas, sobretudo, a respeito o esforço crescente dos Estados em desenvolver políticas públicas de geometria variável, tendo em conta o investimento público feito ao longo dos últimos dois séculos e meio, que estão assentes em dois princípios fundamentais: o princípio da obrigatoriedade escolar e o princípio da igualdade de oportunidades. 
Na verdade, por intermediação de um convite endereçado por uma colega antropóloga brasileira para fazer a visita a esse museu, a ida é logo programada para o primeiro dia da estadia em São Paulo. E nada mais agradável do que ir em companhia do meu amigo e colega Bruno Dionísio.

O fascínio causado por essa incursão de cariz cultural põe-me a pensar justamente nas razões que levam os seus responsáveis a construir um museu sobre um objeto - a língua portuguesa - que, não obstante as suas múltiplas traduções de tangibilidades materiais diversas, não deixa de entrar com toda a força em esferas de produção simbólica. Estas, a língua, suas linguagens e suas ressignificações contextualizadas, não suspendem, por sua vez e em definitivo, as ações humanas. Pelo contrário, ancoram-se nos modos de envolvimento dos atores em múltiplas circunstâncias e em diversas ocorrências, em que os atos comunicacionais são explorados e dinamizados pelos atores em copresença ou por intermediações outras, suportadas ou pela corporalidade humana ou ainda por equipamentos tecnológicos que têm sido continuamente aperfeiçoados entre a segunda metade do século XX e o presente.

Sendo a língua um dispositivo de produção simbólica de carácter atuante, arrastando consigo todas as artes de fazer tudo aquilo que é significante (CERTEAU, 1993; DOSSE, 2007), não deixa, por isso, de produzir significados através dos atos de linguagens entre humanos. Com os seus enquadramentos possíveis, tais atos de linguagens vão dando corpo àquilo que para uns e para outros são considerados contextualmente como significativos. Neste sentido, a língua em ação e os dispositivos dos atos de linguagem que o museu preserva e difunde para os visitantes é, parece-me, uma excelente entrada para pensar as formas contemporâneas de reconhecimento (HONNETH, 2005, 2013; THÉVENOT, 2007), que são o mote desta mesa redonda.

Sobretudo porque o museu dá mostras da pluralidade dos modos de comunicar, de expressões cujos suportes em palavras ou em frases produzem significados diferentes entre os falantes de uma mesma língua e que, por sua vez, ecoam mensagens cujos sentidos são diferencialmente apropriados por públicos distintos, porque desiguais e diferentes, porque se singularizam ou ensaiam essa singularização num apelo hoje cada vez mais insistente às suas 
formas de autenticidade de si (TAYLOR, 1989, 2009). Curiosamente, tais atos expressivos vão acontecendo e reatualizando-se num momento em que um conjunto de equipamentos resultantes da existência da instituição escolar tende a uniformizá-los, a enquadrá-los e a nos dizer qual o formato mais adequado para se exprimir aquilo que se tem de exprimir; para autocensurar aquilo que não se pode ou não se deve dizer, sejam quais forem as circunstâncias; a ensinar quais os tons a empregar nos atos comunicacionais com as pessoas que estão a partilhar essa mesma comunicação, consoante os contextos; enfim, a liberdade do falante nem sempre ocorre e, quando ocorre, pode ser penalizada ou sancionada moralmente (OLIVEIRA, 2008, 2010, 2011) de acordo com aquilo que diz, tendo em conta as situações em que o diz. Assim, tanto os falantes usando a voz ou usando os gestos - quanto os que usam a escrita estão sujeitos a um governo de si (ELIAS, 1989) que, por sua vez, tem de se submeter a um governo das regras gramaticais (LEMIEUX, 2009) - as quais, sendo aceitáveis, atuam ajustadamente às situações. Por seu turno, toda essa autocontenção nos modos de atuar por meio da língua falada ou escrita tem a aceitação formal da escola, uma vez que é nessa casa que as falas e as escritas são não só mais trabalhadas, mas estão mais sujeitas às provas da governação das regras e padrões estabelecidos (THÉVENOT, 2009, 2011).

Contudo, a existência desse governo de regras e de padrões em meio escolar não evita que, quer as modalidades de falantes, quer aqueles que escrevem, não inventem novos termos, novas formas e expressões verbais e escritas, não reduzam ou acrescentem significados a palavras de uso frequente, inventem novas palavras carregadas de outros significados ou, ainda, criem novos formatos e outros dispositivos técnicos para produzi-las e, sobretudo, para difundi-las. Desse modo, as formalizações da língua e dos atos de linguagem se (des)formalizam, pois aquilo que é tornado oficialmente um bem para ser dito ou escrito de uma determinada maneira pode a qualquer altura ser questionado e (re)inventado. As convenções que suportam os acordos ortográficos são o espelho, quer do próprio desacordo relativo a dado formato de governo que regula os jogos entre as palavras comunicadas, quer da utilidade de haver a possibilidade de outro acordo que formalize aquilo que outrora é considerado 
informal, pois esses termos, palavras ou expressões são antes concebidos como discordantes, isto é, pensados como inadequados diante das normas e seus critérios que fundam a anterior convenção linguística.

Por isso, a língua e os atos de linguagem - convencionais e convencionados ou, inversamente, não convencionais e não convencionados - são plurais, tanto em relação aos formatos como em relação aos seus conteúdos. Dessa forma, é sob a batuta de disputas frequentes que a língua e os atos de linguagem fazem a sua história, sendo esta controversa, que suscita debates infindáveis, como aquele que hoje emerge e se desenvolve acoplado ao novo acordo ortográfico dos falantes e escrivães socializados na pátria da língua portuguesa.

Tendo como pano de fundo uma reflexão sobre as formas de reconhecimento em socialidades em que a pluralidade e a diferenciação são suas marcas (in)visíveis, não restam dúvidas de que os espaços da instituição escolar são outra entrada possível para relacionar de que modo os atos de linguagem que ali fluem são ou não capazes de proporcionar formas de reconhecimento entre professores, funcionários e alunos. Pressupondo como hipótese que a pluralidade e a diferenciação são marcas crescentes e caraterizadoras das sociedades contemporâneas, não é descabido equacionar que os atos de reconhecimento emanados nos espaços escolares sejam hoje também objeto de disputas entre seres de gerações diferentes e assumam, por aquelas razões, questionamentos variados, quer nos seus mais diversos contextos, quer nos lugares diferenciados por múltiplas hierarquias comandadas por ordenações de grandeza filiadas em princípios normativos e morais nem sempre compatíveis entre si (RESENDE; CAETANO, 2013). Ora, uma das marcas da diferenciação que integra a forma escolar moderna, reatualizada na contemporaneidade (RESENDE, 2010), são as linguagens e os atos comunicacionais que enformam não só as interações em rede, mas também as sociabilidades que lhes conferem substância significativa.

Contudo, as linguagens e os atos comunicacionais nem sempre produzem substâncias significativamente concordantes entre si, pois uns e outras suscitam, quer do lado do emissor, quer do lado do recetor, ruídos, equívocos, mal-estar e incompreensões diversas, resultantes da empregabilidade de termos, frases, tonalidades de vozes, usos de suporte difusores da voz ou da escrita que 
são desconhecidos, impróprios ou inadequados, indesejados e mesmo inconvenientes, tendo em conta os momentos e os contextos (GOFFMAN, 1963, 1971, 1972, 1981, 1993, 1999).

\section{O INTRIGANTE DO RECONHECIMENTO: ENTRE A PRODUÇÃO ESCOLAR DAS LINGUAGENS - JURÍDICAS E OUTRAS - E OS USOS SOCIAIS DAS LINGUAGENS}

O intrigante dessa dupla entrada para se chegar ao reconhecimento - a língua e os atos de linguagem, de um lado e a escola, de outro - é que as duas instituições, para além das suas materialidades tangíveis, também trabalham com o simbólico e o simbolismo do simbólico. Também são instituições que produzem governos por regras e padrões convencionados, mas que não se aguentam ad eternum. Nesse sentido, uns e outras são constantemente objeto de quebra do acordo, reinventando-se a seguir novas convenções suportadas em novos governos por regras e padrões convencionados. E se as regras das provas que uma e outra estabelecem e obrigam a cumprir (THÉVENOT, 2009), de um lado, e os poderes que as suas provas emanam (DODIER, 2005), do outro, não podem ser desprezíveis, a normalização e estabilização que estas pretendem conferir às ordenações das grandezas (RESENDE; CAETANO, 2013) não estão garantidas para sempre. Isto é, o seu reconhecimento não é absoluto, mas, igualmente, são objeto de disputas e seus (des)acordos não deixam de fazer carreiras históricas complexas.

Explorar na escola pública, composta por diferentes territórios, dentro e fora dos seus muros, as demandas por reconhecimento feitas pelos seus mais frequentes utilizadores exige, do meu ponto de vista, a indagação da razão de o processo de escolarização ser hoje um elemento vital para pensar a centralidade deste objeto não só para se entenderem os atos de linguagem e as formas de engajamento que visam tais aspirações - ser reconhecido na diferença e, reciprocamente, manifestar a capacidade de reconhecer a diferença -, mas também de que modo estas procuras estão sempre acantonadas a processos 
conflituantes, cujos sentidos realistas revelam igualmente respaldos simbólicos que são transpostos para o quotidiano escolar com distintas configurações. Denota-se as composições entre desejar e ser aceite como diferentes e acolher a diferença conforme fronteiras tensas, uma vez que os deslocamentos para um ou outro desses dois lados remetem a uma economia da mutualidade.

Alcançar sempre a reciprocidade desejável recomendada por estas trocas desinteressadas é como estar no fio da navalha, no qual o sujeito que pretende ali se segurar pode a qualquer momento tombar. As consequências públicas dos atos de linguagem habitualmente referenciados como falas do politicamente correto dão conta das (in)seguranças havidas nas transferências mútuas da aceitabilidade das diferenças. Por exemplo, a piada jocosa dita a alguém que se sente e se afirma como diferente nem sempre é aceita como tal pelo destinatário. Por vezes é ajuizada como ofensa moral porque pode ser inesperadamente alvo de chacota e o ato de troçar pode ter o efeito de ser sentido como uma judiaria inaceitável (WERNECK, 2015).

Seguindo esta linha de raciocínio, o mais intrigante é ensaiar pensar o que trazem à reflexão sociológica as formas de reconhecimento escolar requeridas pelas aspirações produzidas por seres - de ambos os géneros - que se manifestam nas suas diferenças, singularizadas ou identificadas com coletivos e/ou movimentos estilizados e estilísticos. Como é do conhecimento público, nem sempre tudo aquilo que resulta da diferença é aceito pela escola e, além disso, é muitas vezes monitorizado por professores, pais e alunos como obstáculo à própria aprendizagem e ao próprio processo de escolarização.

Neste sentido da diferença (LANZA et al., 2013) que é experimentada na escola, seja qual for o contexto, o que se categoriza ou qualifica como diferente pode ser apresentado em dois eixos de valor diferenciado. Se, por vezes, $d a$ diferença resulta a concordância e o reconhecimento daquilo que de positivo a diferença traz ao espaço e à ambiência escolares, outras vezes é o lado negativo que é pontuado, pois da diferença nada de bom se retira para o espaço e ambiências escolares. E, mesmo que da diferença se extraia aquilo que é considerado como positivo ou como negativo, a valorização ou desvalorização da diferença só raramente alcança a unanimidade das vozes. E é por isso que tudo o que 
se alicerça a partir da diferença não escapa a processos conflituantes agónicos (FOUCAULT, 1984), visíveis e/ou invisíveis, assinalados por tonalidades ambivalentes (BAUMAN, 2007), umas mais nítidas, outras mais encobertas e outras ainda obscurecidas.

Para a equipa de pesquisa ${ }^{2}$ que tenho estado a coordenar, as formas de reconhecimento hoje em curso nas escolas de ensino secundário públicas, sob a batuta dos sentidos de orientação dos alunos que as frequentam, têm sido questões importantes e mesmo decisivas para ensaiar reflexões sobre as artes de compor no plural as ordens escolares (RESENDE; CAETANO, 2013) nos seus diversos contextos, mas também para pensar as formas de ressignificação das políticas e ações públicas ao longo da história da escolarização sob mando estatal (RESENDE; GOUVEIA, 2013; RESENDE; CAETANO, 2013). Essas políticas e ações públicas têm aparecido ao longo da história da escolarização suportadas por gramáticas diferentes e plurais (RESENDE; CAETANO, 2012), estando estas, por sua vez, a arcar com os efeitos (in)esperados dos atos de linguagem que lhes dão significâncias várias, não só porque introduzem conceitos, categorias e figuras novas, mas, não menos verdade, porque o

\footnotetext{
2 A equipa de investigação tem estado desde 2004/5 a desenvolver um conjunto de estudos sobre as sociabilidades escolares a partir do ângulo das injustiças escolares experienciadas por professores e alunos. $\mathrm{O}$ primeiro projeto de pesquisa decorre no âmbito de uma bolsa de pós-doutoramento que o autor deste texto recebe da Fundação para a Ciência e Tecnologia (FCT) - SFRH/BPD/20953/2004. Designado como "Socialização política dos estudantes do ensino secundário público em Portugal: quadros normativos, dispositivos e regimes de ação", este projeto decorre com deslocações semestrais (nos segundos semestres dos anos letivos 2004/05, 2005/06; 2006/07) a França para trabalhar com equipas de investigação francesas sobre o mesmo objeto, estando a coordenação científica a cargo do Professor Jean-Louis Derouet em 2005 e 2006, passando em 2007 para a responsabilidade do Professor Patrick Rayou. Neste projeto trabalham 4 pesquisadores, dos quais saliento, os meus colegas Bruno Dionísio, Pedro Caetano, João Esteves e Miguel Fino. Parte dos dados deste estudo aparece no livro RESENDE (2010) - A sociedade contra a escola? A socialização política escolar num contexto de incerteza. Mais tarde, e no âmbito das atividades do Centro de Estudos de Sociologia da Faculdade de Ciências Sociais e Humanas da Universidade Nova de Lisboa onde sou o investigador responsável do projeto "Género, desigualdade e humilhação: sentimentos de injustiça nas escolas" (PIHM/GC/0085/2008), aprovado no concurso de outubro de 2008, e promovido em conjunto pela Fundação para a Ciência e Tecnologia e a Comissão para a Cidadania e Igualdade de Género. Esse projeto foi concluído em abril de 2012 e a equipa de pesquisadores alarga-se. Para além de contar com a colaboração do bolsista Flávio Martins, conto com o intenso empenho de Inês Vicente, Luís Gouveia, Pedro Caetano, Bruno Dionísio, Alexandre Martins e Cristina Cotovio Martins. Este texto comunga das experiências dessas duas pesquisas realizadas em 8 escolas do ensino secundário público. As escolas escolhidas apresentam morfologias sociais contrastantes e estão localizadas em diferentes municípios: 2 em dois municípios a norte do País e em zonas do interior; 1 escola localiza-se na região mais a sul de Portugal; 1 num município do Alto Alentejo (interior); e das restantes 4 escolas, 2 são do município de Lisboa e as outras 2 do município de Oeiras.
} 
que por vezes parece novo e diferente, não o é, pois o que se verifica é o uso de termos miméticos ou muito próximos, mas com ressignificações distintas dos anteriores (RESENDE, 2003, 2007, 2009, 2010). As mais decisivas são as gramáticas jurídicas que adquirem as suas formas nas maquinarias culturais jurisdicionais (ABBOTT, 1988) definidas pelo Estado no âmbito das suas políticas e ações públicas, às quais se acrescentam todos os outros dispositivos reguladores criados pelos estabelecimentos de ensino - projetos educativos, plano anual de atividade e projeto curricular de turma.

Cogitar sobre as políticas e ações públicas no domínio da educação e do ensino, tendo em consideração o questionamento sobre daquilo que da diferença é possível retirar quando se reflete sobre o reconhecimento, traz ao pensamento uma outra interrogação que não é possível dispensar de todo. É mais sobre o âmbito de uma economia da necessidade do que no âmbito de uma economia da utilidade que a referida indispensabilidade nos convoca a levantar a questão.

Por que razão é hoje a escola pública um território que não deixa de ser objeto de disputas diversas, manifestadas por públicos com distintas qualidades que, para além dos seus status e lugares hierárquicos, não deixam, quer os processos de socialização, quer os processos de escolarização, em mãos alheias? Que significados são possíveis avistar a partir dessas implicações, que são hoje manifestadas em diferentes planos, tais como os modos de acolhimento, as formas de habitar, as manifestações de hospitalidade e as buscas de decência em prol da dignidade de si?

Do nosso ponto de vista, desde os primórdios da fundação da forma escolar moderna, a instituição escolar tem sido pensada como equipada de dispositivos comunicacionais atuantes que visam a preparação das gerações mais novas para o confronto futuro com o mundo. Ora, este desafio acometido pela figura do Estado, particularmente no Ocidente desde o século XIX, tem sido realizado tanto pelo lado dos seus formatos curriculares, calendários, horários, regulamentos e regras, como pelo lado da difusão de saberes disciplinares associados a formatos de trabalho e de relações pedagógicas em correspondências por vezes difíceis de afinar com precisão. E uns e outros não só são objeto de questionamento - com frequência - díspares no tempo, mas tal 
ação também implica o acionamento de operações críticas plurais que fazem confrontar pontos de vista dissemelhantes, pois estão alicerçados em fundamentos, muitas vezes, substantivamente diferentes. Deste modo, é no quotidiano escolar e nas experiências partilhadas por indivíduos e coletivos qualificados pela instituição, que os questionamentos e as operações críticas não só transitam de uns para outros por intermédio das suas formas de atuar, como são por estes apropriados quando conflituam uns com os outros.

Dar ênfase à dupla preparação para o confronto com o mundo - palco plural e paradoxal do confronto entre linguagens e linguajares orais e escritas diferenciadas - propiciada pelo trabalho escolar implica considerar, por um lado, o tempo delongado que este investimento exige à instituição, mas, por outro lado, o questionamento cerrado a que se sujeita esse trabalho de longo curso e que é produzido, quer pelas elites dirigentes do Estado, quer pelos fazedores de opinião, quer ainda pelos cidadãos mais informados e comprometidos com as causas públicas. O carácter crítico a que está sujeito o trabalho escolar em cada momento da sua história e as diversas emanações de uma crise permanente que atravessa o processo de escolarização são razões mais do que suficientes para eleger esta instância como um locus político de primeira grandeza nas nossas socialidades.

Contudo, esse locus político aparece ainda mais reforçado nas convicções humanas, uma vez que à escolarização tem sido somado um sem número de finalidades e os modos de agir daqueles que ali trabalham nem sempre conseguem corresponder, em sua integralidade e globalidade, às expectativas entretanto criadas e espoletadas. Nesse sentido, parece haver (como houve sempre) um desajuste e desencanto entre as expectativas sociais depositadas na sua realização após a saída da escola e aquilo que realmente conseguem alcançar, fazer e dizer quando os seres socializados politicamente por esta instituição (RESENDE, 2010) se confrontam com o mundo que é revestido por mundos plurais onde o comum do quotidiano - e das instituições - (DESCOMBES, 1996) se faz, desfaz e refaz em permanência.

Esse hiato entre as expectativas produzidas e efetivamente consumadas impelem os atores a se confrontarem face ao bem comum e em si (RESENDE, 
2007) adquirido no final da sua escolaridade. Em certo sentido, o diploma obtido é a prova legítima assegurada pelo direito, a qual confronta no quotidiano com outras provas legítimas que ali também circundam e circulam, fundadas por outros regimes de envolvimento de ação fora do espaço público (THÉVENOT, 2006) e pelo regime de envolvimento da ação em prol da justiça e da justeza (BOLTANSKI, 1990). Desse modo, os atores entram num movimento crítico (DODIER, 2005) que apresenta a dificuldade em se estabilizar no tempo, nomeadamente, na atual contemporaneidade.

O confronto entre diversas provas legítimas fundadas em múltiplos critérios, normativos e normatividades morais distintas, reenvia de novo à escola o problema da crítica, uma vez que o bem em si, que é a escolarização, não traz aos escolarizados (em geral) a estabilidade das formas da crítica. E qual é a razão dessa instabilidade?

Prende-se a meu ver com a erosão ou o declínio de dois princípios que se mantêm como basilares para a escola como instituição, sobretudo, agência pública. De um lado, temos o princípio da obrigatoriedade escolar. Do outro lado, aparece o princípio da igualdade de oportunidades.

A conjugação pelo Estado do entrecruzamento desses dois princípios que têm estado a orientar as políticas públicas, mas também têm delimitado a pauta das suas ações, tem sido fundamental para a consolidação da forma escolar moderna contemporânea. Por outro lado, a persistência desses dois princípios como orientadores das políticas públicas educativas no Ocidente tem obtido a aprovação dos cidadãos, como mostram as estatísticas quer relativas à procura escolar, quer relativas à crescente redução do abandono e insucesso escolares (ALMEIDA; VIEIRA, 2006; RESENDE, 2010). Assim, se a naturalização desses dois princípios parece ser uma constante, ao longo do tempo a experiência escolar que delas é resultante já não é equivalente entre os seres que habitam e trabalham na escola. E, das suas consequências, não é desdenhável colocar a hipótese de o insuportável também ali morar, uma vez que professores e alunos se têm de suportar mutuamente, mesmo quando uns (independentemente do seu peso estatístico) não manifestem o desejo de ali continuarem a estar. Perante a insistência das políticas em prol da reversibilidade escolar 
(DIONÍSIO, 2018) - medidas para reduzir os números do insucesso e abandono escolar -, a maquinaria jurisdicional (ABBOTT, 1988) das ações políticas limitam as suas saídas definitivas.

\section{PERCEÇÃO DAS EXPERIÊNCIAS ESCOLARES: DAS DESIGUALDADES ÀS INJUSTIÇAS NO EIXO PROBLEMÁTICO DO RECONHECIMENTO}

A persistência de desigualdades escolares experimentadas ao longo de escolarizações mais prolongadas é um dos sinais dessa não equivalência. Nem todos ultrapassam do mesmo modo as provas escolares, nem todos percorrem os mesmos itinerários escolares, nem todos ainda obtêm diplomas com valores estabilizados no mercado de trabalho e, finalmente, nem sempre o diploma faz corresponder um posto de trabalho de valor material e simbólico equivalente.

A erosão ou o declínio daqueles dois princípios não se revela tanto na procura ou na crença sobre aquilo que eventualmente se pode obter através da escolarização. O seu desgaste parece antes advir da perda de legitimidade do poder conferido às provas obtidas pela escolarização que se tem realizado ao longo do tempo justamente por causa dos efeitos provocados pelo aumento da escolaridade obrigatória e das medidas políticas que são tomadas pelo Estado para garantir a todos as mesmas oportunidades escolares. Se a crise da escolarização aflui em cada momento histórico a par do contínuo crescimento da procura e do prolongamento da escolaridade, essa relação cauciona a importância da escola como arena pública e política na qual o movimento crítico (DODIER, 2005) se realiza - insisto - sem estabilizar as operações críticas.

Na verdade, as perdas de legitimidade dos poderes conferidos pelas provas escolares são sobretudo experimentadas no final da escolarização. Contudo, $a$ sua exposição pública, com o aumento do desemprego em geral, mas sobretudo juvenil e qualificado, transporta para o seu interior novos desafios, nomeadamente o desafio da confiança depositada numa instância que produz um bem comum e um bem em si (RESENDE, 2007) que incita a crenças e inquietudes diversas. 
Na verdade, e não obstante a instabilidade societal e as operações críticas produzidas de dentro e fora da escola, os alunos e suas famílias continuam a apostar na escolarização, ajustando-se às possibilidades que esta confere, sem descartar a assunção de trajetórias sinuosas quando a sequencialidade pretendida não é conseguida. Os futuros que esta hoje oferece são enformados pela incerteza e pela indeterminação (VIEIRA; PAPPÁMIKAIL; RESENDE, 2013). São também, por isso mesmo, futuros mais abertos que outrora (VIEIRA; PAPPÁMIKAIL; RESENDE, 2014).

Apesar das ambiguidades e ambivalências experimentadas no decurso da escolarização e das dúvidas quanto ao futuro, a escolarização é olhada como uma plataforma constituída por matrizes diversas e matizadas por expectativas múltiplas. Entre essa multiplicidade, a mobilidade não é descartada, mas é vista mais no plano individual do que coletivo. Para além da tangibilidade dos ganhos materiais e aquilo a que habitualmente se associa a uma vida boa, outros aspetos são ainda expectáveis pelos seres que a habitam.

O investimento de forma (THÉVENOT, 1986) na Educação para a cidadania, seja qual for o seu formato institucionalizado, continua a ser importante no trabalho de socialização política realizado pelos professores (RESENDE, 2010). Entrando pela transmissão dos saberes ou pela administração dos conflitos disciplinares e/ou de violência, aquilo que a socialização política tem trazido para analisar as relações entre professores e alunos na escola tem tornado possível observar mutações nos sentidos de justiça operados por uns e por outros em diferentes contextos escolares (RESENDE; GOUVEIA, 2013; RESENDE; CAETANO; DIONÍSIO, 2014).

As razões de tais transformações são múltiplas. Socorro-me das mudanças ocorridas na morfologia escolar sob um duplo processo: de um lado a crescente massificação e do outro lado a quebra demográfica que se tem manifestado em Portugal. Para além destas, uma outra é significativa: o maior sucesso feminino em quase todos os percursos escolares e uma maior permanência na escola, mais notórias nas recentes coortes em idade escolar (ALMEIDA; VIEIRA, 2006).

Às alterações no plano da morfologia, acrescentam-se outras agora no plano das políticas públicas. De facto, e em certa medida para responder à 
corrosão da confiança nos poderes conferidos pelas provas escolares, visível ainda na sua distribuição assimétrica e na sobreposição das grandezas mercantil e industrial em que assentam as políticas públicas atuais (RESENDE, 2010) - em particular no âmbito das políticas sociais - o Estado desdobra-se em acentuar a deslocação da responsabilidade na distribuição justa do bem comum escolar para a escola e para o indivíduo.

As políticas de descentralização de competências escolares destinadas aos municípios ${ }^{3}$, as medidas políticas que visam o agrupamento das escolas que estão próximas entre si e as medidas dispostas a atribuir-lhes maior autonomia são exemplos que fazem transportar de uma forma mais acentuada para dentro dos estabelecimentos os dilemas e questionamentos, quer sobre o modo que se deve operar uma distribuição justa dos bens escolares entre as gerações mais novas, quer sobre o modo como os adultos os preparam para o confronto com o mundo quando terminarem a sua escolaridade.

A deslocação de competência e as apostas na autonomização dos estabelecimentos de ensino feitas pelo Estado têm trazido às escolas outros desafios interessantes. Tendo em conta aquilo que traz a instabilidade na confiança dos poderes legitimados pelas provas conferidas pela escolarização à própria experiência escolar, o que se tem assistido é a um movimento crítico da parte de muitos docentes assente na desqualificação das grandezas mercantis e industriais em que se funda a prova do mérito, da livre concorrência entre projetos de escola acordados em modelos pedagógicos diferenciados - uns democráticos, outros seletivos e elitistas -, mas também na livre escolha dos locais de ensino por parte dos pais. Se uns os atacam, há outros que se conformam com a sua existência e outros ainda que os defendem, muitas vezes de forma tácita e não verbalizada.

A estes dilemas junta-se um outro não despiciendo: a redução drástica do número de alunos em idade escolar em virtude da diminuição das taxas

\footnotetext{
Das políticas educativas marcadas pela descentralização de competências, salientamos a importância dos municípios na monitorização e controlo das instalações das escolas do Ensino Básico e do Pré-Escolar e na cooperação com as escolas em domínios das cantinas e de outros programas sociais, tais como o transporte dos alunos, em particular nos municípios do interior do país, onde a escolas básicas se encontram muito afastadas das suas residências. Por outro lado, ainda no quadro destas políticas, o Estado, através das ações públicas do Ministério da Educação, territorializa de outro modo os estabelecimentos de ensino agrupando-os de acordo com a proximidade territorial das escolas de ciclos de ensino diferentes.
} 
de fecundidade e de natalidade. Assim, para responder a estes problemas, as escolas tendem a definir um conjunto de políticas, a saber:

1. Políticas de acolhimento;

2. Políticas de habitar;

3. Políticas de hospitalidade;

4. Políticas de decência (RESENDE, 2012).

\section{UM FINAL EM ABERTO: AS ARTES DE (RE)EQUACIONAR O RECONHECIMENTO NAS ESCOLAS - DA HOSPITALIDADE À DECÊNCIA}

Não sendo aqui possível explorar todas as questões relacionadas com as artes de fazer as políticas na escola, é meu propósito abordar exclusivamente as políticas de hospitalidade e as políticas de decência. De facto, e como resultado das exigências políticas respeitantes a uma maior permanência dos alunos na escolarização, as escolas são convidadas a desenvolver programas que incentivem a sua vinculação nas escolas.

Mesmo não querendo entrar no jogo da concorrência mercantil, a redução demográfica cria um peso acrescido, uma vez que escola sem alunos não é escola. Assim, são múltiplas as ações e planos que visam produzir para fora uma imagem de escola, de modo a que essa representação de si seja uma mola de captação de alunos ou crie uma dinâmica, nesse sentido. Ora aos formatos usados para se fabricar essa representação de si faz com que a sua comunidade tenda a fazer uma correspondência, não obstante as incongruências e inconsistências de que uns e outros não conseguem escapar.

As ações públicas das escolas sobre este domínio são diversas. Umas orientam-se no plano das relações e do trabalho pedagógico nas salas de aula. Contudo, tais ações estendem-se a outras atividades fora deste âmbito, mas continuam circunscritas no domínio da transmissão dos saberes. As atividades extracurriculares também se inserem nessas políticas de hospitalidade. 
No entanto, as políticas de hospitalidade emanadas pelos órgãos de gestão dos estabelecimentos de ensino confrontam-se com os ideais que estes subscrevem relativamente às suas conceções sobre as finalidades adstritas à distribuição do bem educativo, sobretudo encarado como bem comum. Neste sentido, a educação é um bem cuja distribuição é uma das esferas de justiça contemporânea que não se deve ignorar.

A aquisição dos saberes é posta à prova em cada ano letivo, mas com mais incidência no final de cada ciclo de ensino. A institucionalização dos exames é um dos dispositivos que mede a natureza (ina)adequada dessa distribuição. E entre uma escola para todos, onde a figura do exame não sendo secundarizada não é sacralizada, e uma escola de excelência onde a medida do exame se afigura como central tendo em conta o lugar no ranking escolar que esta vá eventualmente ocupar, as distâncias são diversas tal como são díspares as suas implicações nos planos (THÉVENOT, 2006) postos à prova da hospitalidade.

A educação como bem em si também está contemplada, mas a sua aferição faz-se do lado das sociabilidades. Aqui, a medida prende-se com os resultados esperados da socialização dos corpos e dos comportamentos. Para uns - professores, alunos e pais - o expectável são corpos socializados em que suas ações se orientem por condutas social e moralmente aceitáveis e reconhecíveis. Para outros, aos corpos que conduzem comportamentos assentes em gramáticas reconhecíveis, a questão das operações críticas não é de todo descartável. Uns insistem na sociedade educada como sendo uma das propriedades vitais da socialização política, outros consideram-na incompleta se o investimento de forma não trabalhar também a sociedade cidadã como outra propriedade daquele mesmo projeto socializador.

Contudo, e agora mais da parte dos alunos, as políticas de hospitalidade são constitutivas das sociabilidades escolares de pleno direito, mas por intermediação das políticas de amizade (RAYOU, 1998; RESENDE, 2010). Através da philia, os alunos expõem-se aos outros que contam (TAYLOR, 2005) através dos laços de proximidade (THÉVENOT, 2006; BREVIGLIERI, 2007) que tecem uns com os outros. 
Não sendo a proximidade física dos corpos a única garantia de uma bem-sucedida política de philia na escola, os seus laços também se forjam através de outros suportes, por exemplo os equipamentos tecnológicos que transportam para a escola as virtualidades de alguns traços marcantes das culturas juvenis urbanas. Se estes equipamentos dão alicerce a atos de linguagem com uma simbologia própria e codificada, não deixam também de ser utilizados como meios onde alguns experimentam operações críticas sobre outros, em particular aqueles cujas ações por excesso de proximidade mais os oprimem do que dignificam o seu ser (BREVIGLIERI, 2007; PASQUIER, 2005).

Com ou sem o suporte dos equipamentos tecnológicos aceitáveis nas escolas, pelas políticas de philia, os alunos exploram a sua individuação, a sua singularidade e a sua autenticidade através da sua exposição ao outro que conta e que o classifica como seu amigo. A reciprocidade relacional é um dos imperativos substantivos das políticas de amizade (KARSENTI, 2003; DERRIDA, 2003). Através dela, os amigos trabalham as relações baseadas em ações orientadas pelos valores do afeto, da lealdade e da confiança.

Se as políticas de amizade se fortalecem na confiança mútua, a verdade impera em detrimento do engano. A confiança gera a confidência e entre os amigos tudo se partilha, mesmo as questões mais problemáticas, mais inquietantes e que muitas vezes se enredam no zelar absoluto pela troca de segredos entre si. Mas nem sempre é assim que agem uns com os outros. Há também ações movidas pela piada, por larachas nada benevolentes. Há atritos, brigas, desconsiderações (RESENDE; GOUVEIA, 2013).

Sendo a exploração de si uma das dimensões centrais da adolescência (BREVIGLIERI, 2007), esta só se realiza efetivamente através do outro que lhe está próximo. Mesmo num contexto de incerteza e de indeterminação, essa exploração é objetivada em modos de engajamento da ação de proximidade onde, por vezes, tudo se arrisca, não havendo espaço para o esboço de qualquer forma de agir em plano. As políticas de amizade dificilmente são perpetuadas pela base de uma segurança estrita, quer na confiança, quer na lealdade. 
O jogo da traição também entra nas trocas sem cálculo e, se esta acontece, são postas à prova as interconexões da amizade. Nesse momento, não há lugar para o estranhamento e a dúvida. A figura do hóspede ou vira membro desta aliança ou, se o ato secreto visto por um não é revelado ao outro que é denominado amigo, a expressão da autenticidade da amizade é questionada e pode vacilar.

Apesar da possibilidade de o ser hóspede virar membro por intermediação das políticas de philia, essa viragem - mais do que a sua incompletude - é baseada na incerteza e na indeterminação e nunca é extensiva a toda a comunidade escolar. Havendo esse vínculo, este é projetado no próximo e nos próximos.

Por outro lado, o engajamento na ação do outro não afasta nem a vulnerabilidade por instrumentalização, nem uma certa cegueira resultante da cumplicidade. A vinculação entre os seres não está convencionada por um reconhecimento no abstrato de alguém que lhe é desconhecido, aquilo a que Mead refere com o outro generalizado (MEAD, 2006; JOAS, 2007).

Pelas razões constitutivas destas políticas, a distanciação de si através de uma distanciação do outro que conta está menos garantida à partida. Na maior parte das vezes, o engajamento afetivo-emotivo sobrepõe-se ao envolvimento racional e funcional em plano.

Assim, o direito a ser membro joga-se num outro tabuleiro e através das políticas de decência. Neste domínio, a prova da humilhação desqualifica a dignidade do ser humano rebaixado, em particular quando o ato de rebaixamento se faz por meio da publicitação, em público, perante a generalização a uma comunidade de outros, que pode ou não ser muito extensa.

Degradar a humanidade que reside no outro implica a sua desconsideração. Os atos de desdém que afetam no desrespeito ao outro diminuído fazem parte de práticas quotidianas nas escolas, quer entre adultos e não adultos, quer entre os alunos (RESENDE; GOUVEIA, 2013).

É justamente no plano do insulto moral (CARDOSO OLIVEIRA, 2008) de que os seres são frequentemente sujeitos no quotidiano, que os alunos pugnam pelo respeito e pela consideração como medidas normativas que qualificam 
positivamente a sociedade decente. Ora, a desqualificação do insulto moral igualiza os desiguais e tornam equivalentes as diferenciações que por vezes os singularizam.

Entre diversos insultos morais, aqueles que atingem os modos de gestão do corpo que são marcas da sua identificação como pessoas são os mais denegridos pelos adolescentes e jovens nas escolas. Aviltar alguém atacando a sua aparência corporal em público é um dos piores insultos morais entre os mais novos.

No apoio incondicional aos humilhados em público, as gerações mais novas não deixam de apelar à proteção dos mais velhos - os professores. Os modos de envolvimento dos professores com vista a zelar pelo outro desconhecido ou não - mas que é sujeito a atos de humilhação verbal ou comportamental - são habitualmente requeridos pelos discentes em contexto escolar.

Aqui o relativismo parece não imperar, uma vez que nenhum contexto é contemporizado como um local aceitável para atos de humilhação de uns sobre os outros. A não condescendência relativa ao insulto moral é ainda mais acentuada se este é explicitado, ou melhor, se este é objeto de publicitação junto de outros conhecidos ou desconhecidos. O insulto moral é assim o lado perverso e humilhante, exprimindo a não garantia da decência como arma política, isto é, impedindo o humilhado, sujeito a uma ação de desqualificação no absoluto, de denunciar tal ato e requerer as reparações, sobretudo aquelas que não são ainda contempladas pela maquinaria cultural da jurisdição cível ou criminal.

Neste ponto não é possível deixar de referir os jogos de linguagem que alimentam a humilhação - com graus de (in)visibilidades distintas - e os que nutrem as operações críticas usando ou não os procedimentos de denúncia que o governo por regras e objetivos (THÉVENOT, 2009, 2011) disponibiliza aos agredidos. Na verdade, os formatos e conteúdos dos atos de humilhação e, correspondentemente, os formatos e conteúdos das operações críticas que os desqualificam são tão plurais quanto os atos de linguagem comunicacional que os tornam tangíveis, quer do ponto de vista da sua materialidade, quer do ponto de vista do simbólico. E aqui voltamos ao início da nossa fala. 


\section{REFERÊNCIA}

1. ABBOTT, Andrew. The system of professions: an essay on the division of expert labour. Chicago: University of Chicago Press, 1988.

2. ALMEIDA, Ana Nunes; VIEIRA, Maria Manuel. A escola em Portugal. Lisboa: Imprensa de Ciências Sociais, 2006.

3. BAUMAN, Zigmunt. Modernidade e ambivalência. Lisboa: Relógio d’Água, 2007.

4. BOLTANSKI, Luc. L'amour et la justice comme compétences: trois essais de sociologie de l'action. Paris: Éditions Métailié, 1990.

5. BREVIGLIERI, Marc. L'arc expérientiel de l'adolescence : esquive, combine, embrouille, carapace et étincelle... Éducation et sociétés, Paris, v. 19, p. 99-113, 2007.

6. CERTEAU, Michel de. L'invention du quotidien: arts de faire. Paris: Éditions du Seuil, 1990. v. 1.

7. CERTEAU, Michel de. La culture au pluriel. Paris: Éditions du Seuil, 1993.

8. DERRIDA, Jacques. Políticas da amizade. Lisboa: Campos das Letras, 2003.

9. DESCOMBES, Vincent. Les institutions du sens. Paris: Éditions du Minuit, 1996.

10. DIONÍSIO, Bruno. Políticas da reversibilidade: extensões e opressões da justiça escolar. ETD- Educação Temática Digital, Campinas, v. 20, n. 2, p. 455-474, 2018.

11. DODIER, Nicolas. O espaço e o movimento crítico. Forum Sociológico, Lisboa, n. 13-14, p. 239-277, 2005.

12. DOSSE, François. Michel de Certeau: le marcheur blessée. Paris: La Découverte Poche, 2007.

13. ELIAS, Norbert. O processo civilizacional: investigações sociogenéticas e psicogenéticas - transformações do comportamento das camadas superiores seculares do Ocidente. Lisboa: Publicações Dom Quixote, 1989. v. 1.

14. FOUCAULT, Michel. Le pouvoir, comment s'exerce-t-il? In: DREYFUS, Hubert; RABINOW, Paul (org.). Michel Foucault: un parcours philosophique. Paris: Gallimard, 1984. p. 308-321.

15. GOFFMAN, Erving. Behavior in public places: notes on the social organization of gatherings. Glencoe: Free Press, 1963.

16. GOFFMAN, Erving. Relations in public: micro studies of the public order. London: Allen Lane, 1971.

17. GOFFMAN, Erving. Interaction ritual: essays on face-to-face behavior. London: Allen Lane, 1972. 
18. GOFFMAN, Erving. Forms of talk. Oxford: Oxford University Press, 1981.

19. GOFFMAN, Erving. A apresentação do eu na vida de todos os dias. Lisboa: Relógio d’Água, 1993.

20. GOFFMAN, Erving. A ordem da interação. In: WINKIN, Yvés (org.). Os momentos e os seus homens. Lisboa: Relógio d’Água, 1999. p. 190-235.

21. HONNETH, Axel. La réification: petit traité de théorie critique. Paris: Gallimard, 2005.

22. HONNETH, Axel. La lutte pour la reconnaissance. Paris: Gallimard, 2013.

23. JOAS, Hans. Georg Herbert Mead: une réévaluation contemporaine de sa pensée. Paris: Economica, 2007.

24. KARSENTI, Bruno. L'amitié se donne-t-elle ? In: JANKÉLÉVITCH, Sophie; OGILVIE, Bertrand (org.). L’amitié. Paris: Hachettes, 2003. p. 91-103.

25. LANZA, Elena Cogato; PATTARONI, Luca; PIRAUD, Misha; TIRONE, Barbara. De la difference urbaine. Genève: Métisses Presses, 2013.

26. LEMIEUX, Cyril. Le devoir et la grace. Paris: Economica, 2009.

27. MEAD, George Herbert. L'esprit, le soi et la société. Paris: Presses Universitaires de France, 2006.

28. OLIVEIRA, Luís Roberto Cardoso de. Existe violência sem agressão moral? Revista Brasileira de Ciências Sociais, São Paulo, v. 23, n. 67, p. 135-146, 2008.

29. OLIVEIRA, Luís Roberto Cardoso de. A dimensão simbólica dos direitos e a análise de conflitos. Revista de Antropologia, São Paulo, v. 53, p. 452-473, 2010.

30. OLIVEIRA, Luís Roberto Cardoso de. Conceções de igualdade e cidadania. Contemporânea, São Carlos, , v. 1, p. 35-48, 2011.

31. PASQUIER, Dominique. Cultures lycéennes: la tyrannie de la majorité. Paris: Éditions Autrement, 2005.

32. RAYOU, Patrick. La cité des lycéens. Paris: L’Harmattan, 1998.

33. RESENDE, José Manuel. O engrandecimento de uma profissão: os professores do ensino secundário público no estado novo. Lisboa: Fundação Calouste Gulbenkian, 2003.

34. RESENDE, José Manuel. Por uma sociologia política da educação: o xadrez das políticas públicas educativas em Portugal no Estado Novo. In: VIEIRA, Maria Manuel (org.). Escola, jovens e media. Lisboa: Imprensa de Ciências Sociais, 2007. p. 231-266.

35. RESENDE, José Manuel. Political socialization and school justice: the point of view of secondary school teachers in Portugal. In: RESENDE, José Manuel; 
VIEIRA, Maria Manuel. (org.). The crisis of schooling? Learning, Knowledge and Competences in Modern Societies. Cambridge: Cambridge Scholars Publishing, 2009. p. 79-91.

36. RESENDE, José Manuel. A Sociedade contra a escola? A socialização política escolar num contexto de incerteza. Lisboa: Edições Piaget, 2010.

37. RESENDE, José Manuel. A escola como territórios de envolvimentos políticos: as gramáticas de socialização política nos encontros dos professores com os alunos. In: CASA-NOVA, Maria José; BENAVENTE, Ana; DIOGO, Fernando; ESTEVÃO, Carlos; LOPES, João Teixeira (org.). Cientistas sociais e responsabilidade social no mundo atual. Vila Nova de Famalicão: Húmus, 2012. p.133-159.

38. RESENDE, José Manuel; GOUVEIA, Luís. As artes de fazer o comum nos estabelecimentos de ensino: outras aberturas sociológicas sobre os mundos escolares. Forum Sociológico, v. 23, p. 97-106, 2013.

39. RESENDE, José Manuel; CAETANO, Pedro. Da philia à hierarquia na escola: composições na ordem escolar? In: VIEIRA, Maria Manuel; RESENDE, José Manuel; NOGUEIRA, Maria Alice; DAYRELL, Juarez; MARTINS, Alexandre; CALHA, António (org.). Habitar a escola e as suas margens: geografias plurais em confronto. Portalegre: ESE do Instituto Politécnico de Portalegre, 2013.

40. RESENDE, José Manuel; CAETANO, Pedro. Socialização política na escola secundária portuguesa: as composições do Projeto Estatal Imaginado de Cidadania e as Gramáticas Políticas Disponíveis. In: DAYRELL, Juarez; NOGUEIRA, Maria Alice; 41. RESENDE, José Manuel; VIEIRA, Maria Manuel (org.). Famílias, escolas e juventude: olhares cruzados Brasil-Portugal. Belo Horizonte: Editora UFMG, 2012.

41. RESENDE, José Manuel; CAETANO, Pedro; DIONÍSIO, Bruno. Das experiências da (des)qualificação das pessoas à precaridade dos laços entre os seres que habitam o mundo escolar. Dilemas, Rio de Janeiro, v. 7, n. 1, p. 11-38, 2014.

42. TAYLOR, Charles. Sources of the self. Cambridge: Cambridge University, 1989.

43. TAYLOR, Charles. Le malaise de la modernité. Paris: Les Éditions du Cerf, 2005.

44. TAYLOR, Charles. A ética da autenticidade. Lisboa: Edições 70, 2009.

45. THÉVENOT, Laurent. Les investissements de formes. In: THÉVENOT, Laurent (ed.). Conventions économiques. Paris: Presses Universitaires de France, 1986. p. 21-71.

46. THÉVENOT, Laurent. L'action au pluriel: sociologie des régimes d’engagement. Paris: Éditions la Découverte, 2006.

47. THÉVENOT, Laurent. Reconnaissances: avec Paul Ricœur et Axel Honneth. In: DELACROIX, Christian; DOSSE, François; GARCIA, Patrick (org.). Paul Ricoeur et les sciences humaines. Paris: La Découverte, 2007. p. 127-143. 
48. THÉVENOT, Laurent. Governing life by standards: a view from engagements. Social Studies of Science, Thousand Oaks, v. 39, n. 5, p. 793-813, 2009.

49. THÉVENOT, Laurent. Grand résumé de l’action au pluriel: sociologie des régimes d’engagement. SociologieS, [S.1.], 2011. Disponível em: http://sociologies.revues. org/3572. Acesso em: 18 fev. 2018.

50. VIEIRA, Maria Manuel; PAPPÁMIKAIL, Lia.; RESENDE, José Manuel. Forced to deal with the future: uncertainty and risk in vocational choices among Portuguese secondary school students. Sociological Review, Thousand Oaks, v. 61, p. 745-768, 2013.

51. VIEIRA, Maria Manuel; PAPPÁMIKAIL, Lia.; RESENDE, José Manuel. Em busca de si: a construção das escolhas escolares no ensino secundário português. Educação em Revista, Belo Horizonte, v. 14, n. 2, p. 7-24, 2014.

52. WERNECK, Alexandre. Dar uma zoada? Botar a maior marra? Dispositivos Morais de jocosidade como formas de efetivação e sua relação $\mathrm{cm}$ a cítica. Dados, Rio de Janeiro, v. 58, p. 187-222, 2015. 